\title{
Culture and Eating Disorders: A Historical and Cross-Cultural Review
}

\author{
Merry N. Miller AND Andrés J. Pumariega
}

CULTURAL beliefs and attitudes have been identified as significant contributing factors in the development of eating disorders. Rates of these disorders appear to vary among different racial/ethnic and national groups, and they also change across time as cultures evolve. Eating disorders are, in fact, more prevalent within various cultural groups than previously recognized, both within American ethnic minorities and those in other countries. This review examines evidence for the role of culture as an etiological factor for the development of eating disorders. Historical and cross-cultural experiences suggest that cultural change itself may be associated with increased vulnerability to eating disorders, especially when values about physical aesthetics are involved. Such change may occur across time within a given society, or on an individual level, as when an immigrant moves into a new culture. Further research into the cultural factors that promote the development of eating disorders is much needed. Understanding how cultural forces contribute to the development of disorders is needed so that preventive interventions can be created.

Cultural beliefs and attitudes have been identified as significant contributing factors in the development of eating disorders. Rates of these disorders appear to vary among different racial/ethnic and national groups, and they also change across time as cultures evolve. This article presents a review of the literature, compiled through an initial Medline literature search from 1968-2000 and supplemented with referenced articles. The dearth of epidemiological studies in this area, especially in underdeveloped nations, requires an open ex-

Merry N. Miller, MD, is Professor and Interim Chair of the Department of Psychiatry at the James H. Quillen College of Medicine, East Tennessee State University. Andrés 7. Pumariega, $M D$, is Professor and Director of Child and Adolescent Psychiatry at the James H. Quillen College of Medicine, East Tennessee State University.

Address correspondence to Merry N. Miller, MD, Department of Psychiatry and Behavioral Sciences, James H. Quillen College of Medicine, East Tennessee State University, Box 70567, Johnson City, TN 37614; phone: 423-439-7386; fax: 423-439-7710; E-mail: millerm@etsu.edu. ploration of all reports that can be found. However, as will be discussed further, many of these reports are anecdotal and represent a limited perspective on the larger issue of how widespread the eating disorders have become.

The primary eating disorders to be discussed in this review are anorexia nervosa and bulimia nervosa, which are the principal eating disorders identified in the fourth edition of the Diagnostic and Statistical Manual of Eating Disorders (DSM-IV; American Psychiatric Association, 1994). In addition to those individuals who meet the full criteria for these disorders, many individuals exhibit subclinical levels of these disorders (and may be classified as having "eating disorder not otherwise specified"). Because the definitions of these disorders have also evolved over time, this review also describes in broad terms pathological eating behaviors and disorders across time and across cultures.

Another potential type of eating disorder that has been receiving recognition recently is binge-eating disorder, in which one engages in "binges" of excessive eating with- 
out a compensatory behavior to eliminate the food such as purging (DeZwaan, Mitchell, Raymond, and Spitzer 1994). Individuals with binge-eating disorder typically develop obesity and the health problems that are associated with obesity. However, it is fallacious to assume that all obesity is secondary to bingeeating disorder, as is known from genetic studies of obesity. There is a need for more study of the boundary between binge-eating disorder and obesity (Greeno, Wing, and Shiffman 2000). Racial differences are beginning to be identified in binge-eating disorder and merit further study (Striegel-Moore, Wilfley, Pike, Dohm, and Fairburn 2000). There may be cross-cultural issues as individuals move from traditional non-Western dietary and activity patterns into Western cultures. This review focuses primarily on the former two conditions, because these have traditionally been identified as the eating disorders, but it is worth noting that binge-eating disorder is another eating disturbance that has recently been conceptualized.

\section{ROLE OF WESTERN IDEALS}

The idealization of the thin body type within Western societies has been identified as a possible factor leading to the development of anorexia nervosa (Bruch 1962). Garner, Garfinkel, Schwartz, and Thompson (1980) demonstrated an increasing gap between the weights of women in the general population versus the weights of women who serve as role models for attractiveness. The mass media has been blamed by many for a possibly pathogenic role in promoting attitudes about body and self that enhance the risk for developing an eating disorder (Becker and Hamburg 1996; Stice, Schupak-Neuberg, Shaw, and Stein 1994).

As the image of beauty that is promoted has changed, women in this society show increasing evidence of dissatisfaction with their bodies and pressure to conform to this ideal. Increases in the number of diet articles (Garner et al. 1980) and in dieting behavior ( $\mathrm{Ny}$ lander 1971) even among preadolescent girls
(Hawkins, Turell, and Jackson 1983; Maloney, McGuire, Daniels and Specker 1989) reflect reactions to this dissatisfaction. Such dieting behavior is now believed to sometimes be the precursor to the development of an eating disorder. In addition, certain subpopulations such as ballerinas and models have been associated with particularly high risk for developing eating disorders due to heightened levels of pressure for thinness (Garner and Garfinkel 1980; Russell 1985). Thus changing sociocultural factors have been identified as the most plausible explanation for rising rates of eating disorders for American and Western women.

Men have been less likely to develop eating disorders (Walsh 1997), which is consistent with the lower level of social emphasis on male body weight and shape (Rolls, Fedoroff, and Guthrie 1991). Those men who develop eating disorders closely resemble female eating disorder patients in terms of their dissatisfaction with body image (Olivardia, Pope, Mangweth, and Hudson 1995), and again certain subpopulations of men such as male wrestlers and jockeys appear to be at increased risk of developing an eating disorder because their professions require weight restriction (Mickalide 1990). A possible association between male homosexuality and the development of eating disorders has also been suggested (Carlat and Camargo 1991; Herzog, Newman, and Warshaw 1991; Silberstein, Mishkind, Striegel-Moore, Timko, and Rodin 1989), which may reflect a male subculture that places them more at risk for disordered eating though its emphasis on appearance and slimness (Silberstein et al. 1989).

Although contemporary emphasis on the Western ideal of beauty has been blamed for increases in the prevalence of eating disorders across the last several decades, a more thorough review of history reveals that these disorders have been present in other eras.

\section{HISTORICAL PERSPECTIVE ON ANOREXIA NERVOSA}

History shows that disordered eating behaviors have been reported since ancient 
times in some cultures, but their apparent frequency has varied greatly over time. Ancient Greek and Egyptian cultures have records that indicate ritual fasting for brief periods, but no prolonged fasting as is seen in anorexia nervosa is suggested in their records. A spiritually motivated asceticism in ancient Eastern religions led to self-starvation that resembles anorexia nervosa today (Bemporad 1996). Further examples of asceticism are found at other times in history and in other cultures, such as with early Christians and in "gnostic cults" (Lacey 1982), who engaged in severe fasting as a radical reaction against the hedonism and materialism of that age. This spiritual motivation contrasts sharply with the desire for thinness that is believed to be a fundamental characteristic of anorexia in the DSM-IV.

In contrast, during the following era of the Dark Ages, a series of disasters led to a period in which hunger and deprivation were widespread; during this period willfull self-starvation appears, with a few exceptions, to have been absent (Bemporad 1996). Later, during the late Middle Ages and the early Renaissance periods, self-starvation that was spiritually motivated reappeared, with many women who fasted acquiring the status of saints in the Roman Catholic Church (Bell 1985).

During the 17 th and 18 th centuries, a gradual transformation took place in the interpretations that were made of fasting women. During the Reformation, the belief developed that instead of being "holy," such starving women were possessed by the devil. At times self-starvation was seen as a source of entertainment (Bergh and Sodersten 1998). Later these fasting women were seen to sometimes be frauds. In time they came to be seen as physically or mentally ill, much as they are regarded today (Bemporad 1996).

Other periods in history have also valued thinness. During the 19th century, the "tubercular look" was idealized, and it was considered glamorous to look sickly (Sontag 1978). Anorexia nervosa became recognized as a medical disorder in the late 19th century (Silverman 1997). Its similarity to pituitary atrophy lead investigators to search for neuroendocrine causes and mechanisms, a search that is very much alive today (Brumberg 1988; Gold et al. 1986). However, it was recognized that anorexia differs clinically in significant ways from the presentation of pituitary disease, especially the patient's course of illness, physical manifestations, and level of distress. Additionally, it is noteworthy that these original descriptions from the turn of the century did not include a fear of fat, which is considered central to the diagnosis of anorexia nervosa today (Sheehan and Summers 1948).

Psychological hypotheses about the causation of anorexia nervosa dominated the first half of the 20th century. These began with the early psychodynamic theorists' focus on unconscious conflicts about sexuality and wishes for oral impregnation (in the context of then prevailing cultural mores about sexuality), as well as adolescent rebellion and regression to the oral stage of development (Sheehan and Summers 1948; Waller, Kaufman, and Deutsch 1940). The advent of object relations theory and its focus on the role of early infantparent interactions on personality development led to a reformulation of the dynamic underpinnings of eating disorders. Bruch (1973) and Selvini-Palazzoli (1963) were the first both to emphasize the anorexics' lack of a sense of autonomy and differentiation from their mother and their search for control as a result of their inability to master adolescent separation and individuation. They also placed a parallel emphasis on a more transactional psychotherapy with a focus on self-other differentiation. Other theorists similarly emphasized the theme of conflicts over separation and individuation from the family perspective (Minuchin, Rosman, and Baker 1978; SelviniPalazzoli 1963). Bruch (1985) went on to comment on how patients with eating disorders in this era did not present with the same need for control and mastery but demonstrated a "me too" quality and were not as sincere in their pursuit of thinness and control.

\section{HISTORICAL PERSPECTIVES ON BULIMIA}

Earlier psychodynamic theorists treated binge purging as part of the symptom complex 
found in anorexia nervosa, with a focus on the symbolic significance of the behaviors involved (search for oral comfort, rejection of oral impregnation, or ejection of the internalized maternal image; Swift and Letven 1984). Bulimia nervosa as a separate diagnostic entity was only first identified in 1979, and there has been some speculation that it may represent a new disorder rather than one that was previously overlooked (Russell 1979). This premise, however, is not supported by review of historical precedents, and cultural forces can be observed to play a role in the appearance of bulimic behaviors throughout history.

In contrast to the ascetically motivated self-deprivation described previously, other historical accounts from ancient Egypt, Greece, Rome, and Arabia describe more hedonistically driven behaviors which resemble bulimia (Nasser 1993). Overeating and induced vomiting in ancient times are well known and do not necessarily represent an ancient equivalent of bulimia nervosa (Russell 1997). In ancient Rome, vomitoriums were used for the purpose of swallowing an emetic after heavy feasting. Excessive eating followed by habitual vomiting was reportedly practiced by the wealthy elite at that time, which may represent a historical variant of bulimia that was promoted by social forces (Crichton 1996). In addition, Nasser (1993) has provided accounts of purging in ancient Egypt that was medically endorsed. Again, this self-induced vomiting lacks the desire for thinness as a motivating force, and does not necessarily reflect an ancient form of bulimia. It does suggest an early precedent for bulimic behaviors.

Thus historical review suggests that eating disorders may have been present for thousands of years. Disordered eating behaviors documented throughout most of history raise much question about whether eating disorders are in fact a product of current social pressures (Bemporad 1996).

\section{EATING DISORDERS AMONG ETHNIC MINORITY GROUPS}

Another controversy about eating disorders exists regarding contemporary social factors associated with the presence of this pathology. It has previously been believed that eating disorders occurred almost exclusively in upper socioeconomic groups within Western nations (Bruch 1973), and most research suggests that eating disorders continue to be found predominantly among White individuals in Western-oriented countries (Altabe 1996; Thompson 1996). However, evidence is now emerging that eating disorders in fact occur in a wide range of ethnic, cultural, and socioeconomic groups within the United States, with estimates of the prevalence of anorexia and bulimia in non-Caucasians ranging from $1 \%$ to $4 \%$, depending on age, ethnicity, and location of the subject (Dolan 1991).

Early studies identified sociocultural factors within American society that are associated with the eating disorders. Eating disorders had traditionally been associated with Caucasian upper socioeconomic groups, with a "conspicuous absence of Negro patients" (Bruch 1966). Rowland (1970) found that a higher proportion of individuals with eating disorders from his clinical sample came from lower-class (60\%) and middle-class (34\%) backgrounds, with a majority of Italian and Jewish individuals (17 of 30) and a high percentage of Catholics (47\%). He suggested that Jewish, Catholic, and Italian religious/cultural origins may lead to a higher risk of developing an eating disorder due to cultural attitudes about the importance of food. The inferences drawn from these earlier studies were that ethnic and racial differences in the presence of eating disorders were linked to socioeconomic status (SES). This has been disputed by more recent studies. Andersen and Hay (1985) compared 8 African Americans and 120 Caucasians with eating disorders to each other and to 21 African American psychiatric controls. They found no statistical differences in demographic or clinical characteristics between the two groups of patients except in age of onset (older for African Americans, $p<.025$ ). However, they found that African Americans with eating disorders had a significantly higher socioeconomic level than their non-eating disordered controls $(p<.01)$ but no difference in age of onset. A recent review by Gard and Freeman (1996) of research linking eating disorders with high SES provided surprising re- 
sults. The purported relationship between anorexia nervosa and high SES was found to be poorly demonstrated, and evidence was found to suggest that bulimia nervosa may actually have an opposite relationship. Five studies since the mid-1980s have found an excess prevalence of eating disorders in low socioeconomic groups. Eight studies that support a link with low SES and eating disorders have significant methodological problems; eight other studies fail to support this relationship. The association between the cultural influences of wealth or poverty on the development of eating disorders requires further study.

A number of nonclinical studies have demonstrated that African Americans have different attitudes about weight, body size, and attractiveness than Caucasians, with overall less drive for thinness and greater acceptance of larger body proportions. Rucker and Cash (1992), in a study of 104 African American and White female college students using multiple standardized measures, found that White students held less favorable attitudes about body image $(p<.02)$, body size ideals that were thinner than their perceived size $(p<.001)$, and stricter criteria for perceived body fatness $(p<.02)$ than did African Americans. Greenberg and LaPorte (1996) studied the attitudes of 63 African American and 116 Euro-American males about the attractiveness of different female body forms using a series of silhouettes of different sizes. They found that Euro-American men chose significantly thinner figures as their first choice $(p<.05)$ and their first three choices $(p=.003)$, and they more frequently reported wishing that their girlfriends were significantly thinner $(p=.013)$ than did their African American counterparts. Ashley, Smith, Robinson, and Richardson (1996) used the Eating Disorders Inventory-2 (EDI-2) to study disordered eating pathology in female intercollegiate athletes as compared with nonathletic college subjects. They found that African American female athletes had significantly lower scores than White athletes on the Body Dissatisfaction and Impulse Regulation subscales. Schreiber and colleagues (1996) studied 1,213 African American and 1,166 White girls aged 9 and 10 years of age to evaluate their efforts at weight reduction. They found that African American girls were taller and heavier than their White counterparts but less dissatisfied with their weight, and significantly more African American girls were trying to gain weight. No racial differences were found in the girls' efforts to lose weight or practice chronic dieting. African American women may be protected from developing the body dissatisfaction found in White women, both due to greater receptiveness to the influence of family and friends and to the media images of ideal body form being predominantly White (Rucker and Cash 1992; Thomas 1989).

Recent evidence suggests that the trend among African Americans is toward rising risk for eating disorders. A number of case reports in the 1970s and 1980s first pointed to an increasing frequency of eating disorders among African Americans (Lawlor, Burket, and Hodgin 1987; Pumariega, Edwards, and Mitchell 1984; Robinson and Andersen 1985; Warren and Vande Wiele 1973). More recently, formal studies have confirmed this trend, with white cultural norms having an increasing influence on African Americans. Abrams, Allen, and Gray (1993) found that disordered eating among African Americans was related to assimilation to Caucasian culture as measured by the Racial Identity Attitude Scale for Blacks. A survey of 2,161 readers of Essence, a popular African American fashion magazine, found levels of abnormal eating attitudes and body dissatisfaction that were at least as high as a similar survey of Caucasian women. These included $53.6 \%$ who scored over the clinical cut-off of the Eating Attitudes Test-26 (EAT-26), 72\% who were terrified of gaining weight, $38 \%$ who engaged in binges, $3.5 \%$ who purged through vomiting, and $16 \%$ who abused laxatives. They also found a significant negative correlation $(p<.01)$ between the desire to be thinner and a strong Black identity (Pumariega, Gustavson, Gustavson, Motes, and Ayers 1994). It has been hypothesized that thinness is gaining more value within the African American culture just as it is in Caucasian culture (Hsu 1987). This hypothesis has been supported by recent studies in which no statistical differences in eating or weight-related concerns were found between Caucasian and 
African American females (Altabe 1996). One recent study found significantly higher levels $(p<.01)$ of the drive for thinness in African American girls compared with Caucasians (Striegel-Moore, Schreiber, Pike, Wilfley, and Rodin 1995). These findings support an earlier suggestion by Silber (1986) that the process of acculturation plays an important role in the Black or Hispanic adolescent female who develops anorexia nervosa, because these individuals feel different and may strive to be accepted by means of an extreme adoption of the slim social ideal.

Eating disorders have also been traditionally less prevalent in other ethnic minority groups in the United States. Lucero, Hicks, Bramlette, Brassington, and Welter (1992) compared the frequencies of Asian American and White women found to have clinically significant responses on the EAT-26 and found White women to be 5.5 times more likely to score above the clinical cut-off. However, other studies suggest that U.S. ethnic minority groups are showing a trend toward higher levels of eating disorders (Pate, Pumariega, Hester, and Garner 1992). Pumariega (1986), in an early study comparing a sample of Hispanic adolescent girls with White southern counterparts recruited in school settings, found equal levels of abnormal eating attitudes in the two groups as characterized by percentage with EAT-40 scores above the clinical cut-off (19\% for Whites and $20 \%$ for Hispanics). However, he found a significant correlation between abnormal eating attitudes and acculturation $(p<.05)$ but no association with SES in the Hispanic sample. Hall, Cousins, and Power (1991) examined the relationship between Mexican American mothers' and daughters' judgments of physical attractiveness. One half of the mothers were obese and enrolled in a weight control program; the other half served as normal weight controls. Daughters tended to prefer thinner figures than did mothers; they ranked their ideal figures thinner than their perceived figures; and their overall self-concept was predicted by age, their body size, and their mothers' size. Fisher, Pastore, Schneider, Pegler, and Napolitano (1994) compared 389 urban females, who were predominantly Hispanic and African American, to 268 predominantly White suburban females and found that the percentage scoring above the clinical cut-off on the EAT-26 was comparable in both groups $(15 \%$ to $17.5 \%$, respectively). A recent study of 967 early adolescent girls found that Hispanic girls showed significantly greater body dissatisfaction $(p<.03)$ than did White girls on the Body Dissatisfaction subscale of the EDI. Among the leanest $25 \%$ of girls, both Hispanics and Asians showed significantly greater body dissatisfaction than White girls did $(p<.001$ and $p<.002$, respectively; Robinson et al. 1996). In a study of eating and general psychopathology in a college sample of women, le Grange, Telch, and Agras (1997) found that 109 White and 40 minority women scored similarly on eating disorder and general psychopathology measures. Fitzgibbons and colleagues (1998) compared the severity and correlates of binge eating in a sample of White, African American, and Hispanic women. Binge-eating symptoms were more severe in Hispanics than in Whites or African Americans. Depressive symptoms and weight predicted binge-eating severity in Hispanics, depression alone in Whites, and neither factor predicted binge-eating severity for African Americans. Chamorro and FlorezOrtiz (2000) studied 139 females comprising five generations of Mexican Americans using the Acculturation Rating Scale for MexicanAmericans and the EAT-26. They found that second-generation women endorsed the most disordered eating patterns and the highest degree of concurrent acculturation to mainstream U.S. culture. Additionally, they found a significant positive correlation between acculturation and the eating control subscale of the EAT-26. Cultural beliefs that may have protected ethnic groups against eating disorders may be eroding as adolescents face pressures to acculturate to mainstream U.S. culture (Pumariega 1986).

Cases of anorexia nervosa have been described in Native American girls (Yates 1989). A study of 85 Native American females aged $12-55$ found that $74 \%$ were trying to lose weight using potentially hazardous methods, including purging (24\%), diet pills (41\%), and 
prolonged fasting (33\%) (Rosen, Shafer, et al. 1988). Snow and Harris (1989), in their study of Pueblo Indians (51) and Hispanic (31) girls in the rural Southwest, found that $11 \%$ of the total sample met criteria for bulimia; $87 \%$ and $88 \%$, respectively, worried about being too fat; $43 \%$ and $61 \%$, respectively, fast for extended periods; and $53 \%$ and $65 \%$, respectively engage in binge-eating episodes. Another recent study has reported levels of disordered eating attitudes among rural Appalachian adolescents that are comparable to urban rates, with a higher percentage of girls above the clinical cut-off on the EAT-26 in the more rural schools (24.8\%) compared with the more urban schools $(14.6 \%, p<.0001$; Miller, Verhegge, Miller, and Pumariega 1999). The latter finding contrasts with expectations that eating disorders are more common in urban areas and has been hypothesized to reflect an expanding presence of eating disorders in areas in which mainstream culture as promoted by the media conflicts with more traditional American cultures.

Recent immigrants may be particularly at risk for the development of eating disorders. Van Den Broucke and Vandereycken (1986) studied 14 European exchange students who developed eating disorders after coming to the United States, and Kope and Sack (1989) studied three Southeast Asian refugees who developed anorexia nervosa shortly after their arrival. These authors suggested that the experience of encountering a clash in cultures may precipitate the development of an eating disorder, especially in adolescents who also are suddenly separated from the family of origin and adjusting to new social and familial interaction patterns; therefore these individuals face a serious challenge to individuation.

\section{EATING DISORDERS IN OTHER WORLD REGIONS AND CULTURES}

Outside the United States, eating disorders have been considered to be much more rare. This has been associated with variations across cultures in the ideals of beauty that are admired as well as the socioeconomic development of different nations. In many non-Western societies, plumpness is considered attractive and desirable and may be associated with prosperity, fertility, success, and economic security (Nasser 1988). In such cultures, eating disorders are found much less commonly than in Western nations. Available literature suggests that Western-oriented countries may have a comparable prevalence of eating disorders to the United States. For example, several authors have described a marked increase in the prevalence of anorexia nervosa and bulimia nervosa in Japan (Kamata, Nogami, and Momma 1987; Nakane and Umino 1987). However, in recent years there have also been a number of reports (Ritenbaugh, Shisslak, and Prince 1992) suggesting that the presence of eating disorders in developing, Third World nations appears to be increasing.

\section{Europe}

Rates of eating disorders in European countries appear to be increasing over the last few decades just as they are in the United States. Several authors have studied rates of eating disorders in Sweden (Norring and Sohlberg 1988; Theander 1970), Germany (Steinhausen 1984), Switzerland (Willi and Grossman 1983), England (Lacey and Dolan 1988), Scotland (Kendall, Hall, Hailey, and Babigian 1973), Italy (Rathner and Messner 1993), and the Netherlands (Hoek 1991). Theander (1970) reported a steady increase in the incidence of anorexia nervosa in a defined population in Sweden, rising from 0.12 to 0.45 per 100,000 per year over a 30 -year period. A comparative epidemiological study found consistent increases in the incidence of anorexia nervosa in northeast Scotland, Monroe County (New York state), and Camberwell district (London) from the 1960s to the early 1970s. The average incidence rates were 1.6 (northeast Scotland), 0.66 (Monroe County), and 0.37 (Camberwell) per 100,000 per year. The greatest increase in incidence occurred in northeast Scotland, and Camberwell was the only area where a disproportionate number of patients came from the middle and 
higher classes (Kendall et al. 1973). A followup of the same region in northeast Scotland established a mean annual increase in the incidence rate of anorexia nervosa of $5.3 \%$ from the 1960s to 1991 (Eagles, Johnston, Hunter, Lobban, and Millar 1995). Willi and Grossman (1983) found an increase in the incidence of anorexia in Zurich, Switzerland, from 0.38 per 100,000 per year (1956-1958) to 1.12 per 100,0000 per year (1973-1975). In a followup study of the same region, Willi, Giacometti, and Limacher (1990) found no further significant increases in incidence in 1983 to 1985 (1.43 per 100,000 per year) but found a significant increase in vomiting among patients ( $75 \%$ from 1983 to 1985 from $50 \%$ in previous years). Rathner and Messner (1993) found a minimum point prevalence of $1.3 \%$ for clinical anorexia, $1.3 \%$ for subclinical anorexia, and $0.87 \%$ for subclinical bulimia in a sample of 517 rural schoolgirls in Italy. Hoek (1991) found annual incidence rates of 6.3 per 100,000 per year for anorexia nervosa and 9.9 per 100,000 per year in a representative Dutch primary care population. A study comparing Greek adolescents living in Germany with Greek adolescents living in Greece found that the Greek girls in Germany showed a higher prevalence of anorexia nervosa $(0.4 \%$ vs. $1.1 \%$, respectively; Fichter, Weyerer, Sourdi, and Sourdi 1983). This finding reflects the difficulties faced even by White immigrants from within the European continent in coping with new social influences.

Several studies have examined the eating attitudes and behaviors of non-White minority populations living in Great Britain. Anorexia nervosa has been identified among South Asian children living in Britain (BryantWaugh and Lask 1991). One comparison between Asian and Caucasian girls living in England has revealed that South Asian girls had a greater level of bulimic attitudes than Caucasians as measured by mean scores on the bulimic subscale of the EAT-26 (1.16 vs. 0.57 , respectively, $p<.25)$, though their overall mean EAT-26 scores were not significantly different (Ahmad, Waller, and Verduyn 1994). Another similar comparison also found that South Asian girls living in Britain had higher levels of bulimia nervosa on clinical interview and significantly higher mean EAT-26 scores $(10.6$ vs. $7.7, p<.001)$ than did Caucasian girls. Furthermore, their scores on the EAT26 and the Body Shape Questionnaire were correlated with a more traditional cultural orientation $(p<.0001$ and $p<.05$, respectively) and not with greater Westernization (Mumford, Whitehouse, and Platts 1991). Yet another study comparing eating attitudes and behaviors of British schoolgirls with British versus South Asian extraction found no significant differences between the groups in terms of EAT-26 scores or vomiting behavior, though the mean EAT-26 score for the total sample (35.4) was above the clinical cut-off score. They did find evidence that cultural differences influence eating attitudes in the South Asian girls: Over $40 \%$ of items in an questionnaire measuring resentment of restrictions in traditional culture (such as not being able to chose their own spouse), and over $50 \%$ of items in another questionnaire measuring cultural integration had significant negative correlations with EAT-26 scores (Furnham and Patel 1994). Two other studies of eating disorders in South Asian girls in England reported greater levels of perceived parental control than Caucasian girls as significant risk factors (Ahmad, Walker, and Verduyn 1994; McCourt and Waller 1995). In one of these studies (McCourt and Waller 1995), significantly higher EAT-26 scores were found in the South Asian girls $(p<.05$ to $p<.001)$, with ratings of parental overprotection being significantly correlated to EAT-26 scores $(p$ $<.05$ to $p<.001$, depending on age group). Another study by Hill and Bhatti (1995) found that both South Asian and Caucasian 9-yearold girls in Britain placed high priority on thinness. However, British Asian girls had a significantly higher level of dietary restraint $(p<.01)$ than Caucasian girls did, and it was marginally correlated with a more traditional cultural orientation ( $p=.051)$. These observations have led to the speculation that intrafamilial (e.g., between parents with traditional values and adolescents) as well as intercultural conflicts may lead to internal conflicts and developmental difficulty during adolescence 
for British girls of South Asian background, which may result in an increased risk for eating disorders (Hill and Bhatti 1995).

\section{Asia}

Review of studies of the prevalence of anorexia nervosa in Asia that have been conducted in recent years demonstrates that this disorder does occur in Asia, although it is very rare. Rates of anorexia among females of $0.03 \%$ in Hong Kong and $0.08 \%$ in Japan have been reported in two recent studies (Hsu 1996). Anorexia nervosa was found to be very rare in Malaysia, with 28 females and 2 males out of 60,000 new psychiatric referrals seen by the 17 psychiatrists in the nation over 9 years (Buhrich 1981), and in Singapore, with only seven cases reported in one study (Ong, Tsoi, and Cheah 1982). The incidence of anorexia may be increasing in Hong Kong (Hsu and Lee 1993). Several authors have also described a marked increase in the prevalence of anorexia nervosa and bulimia nervosa in Japan (Nakane and Umino 1987). Kamata and colleagues (1987), in their study of 1,250 females ranging from high school to college, found the prevalence of binge eating to range from $7.5 \%$ among high school students, $8.3 \%$ among college students, to $33.8 \%$ among students in a physical education college. The number of patients in Japan seeking treatment for anorexia nervosa was found to double between 1976 and 1981 (Suematsu, Ishikawa, Kuboki, and Ito 1985). Kuboki, Nomura, Ide, Suematsu, and Araki (1996) conducted an epidemiological survey of Japanese hospitals in 1985 and 1992, and found the prevalence of anorexia nervosa in Japan to be 3.6 to 4.5 per 100,000 among the general population and $6.3-9.7$ per 100,000 among the female population. The clinical picture of anorexia nervosa in Japan has been found to be similar to Western cultures. Surprisingly, Kuboki and colleagues found that the prevalence of bulimia nervosa in Japan in 1992 was much less than the prevalence of anorexia nervosa (1.3-2.5 per 100,000 in the general population and $3.2-4.3$ per 100,000 among females).

In India a study of 580 schoolgirls using the EAT-26 found that $29 \%$ of their sample scored above the recommended thresholds; however, the authors noted that some questions may have been misinterpreted due to cultural or linguistic factors, and only a very small number of girls answered positively to the most specific questions that described abnormal eating behaviors (King and Bhugra 1989). A study of adolescent girls attending school in Pakistan found higher levels of abnormal eating attitudes in the girls most exposed to Western culture (Mumford, Whitehouse, and Choudry 1992).

Cross-cultural comparisons of cases of eating disorders that have been identified have yielded some important findings. In Hong Kong and India, one of the fundamental characteristics of anorexia nervosa is lacking. In these countries, anorexia is not accompanied by a "fear of fatness" or a desire to be thin; instead, anorexics in these countries have been reported to be motivated by the desire to fast for religious purposes or by eccentric nutritional ideas (Castillo 1997). Bodily denial may be a means by which some South Asian women resolve ambivalent demands or achieve selfdetermination (Littlewood 1995). A further motivation reported in Hong Kong has been epigastric fullness or lack of hunger (Hsu and Lee 1993). Such religious ideation behind anorexic behavior is reminiscent of the descriptions of saints from the Middle Ages in Western culture, when spiritual purity rather than thinness was the ideal (Bemporad 1996).

The fact that weight phobia did not emerge as a primary feature of anorexia nervosa until around 1930 combined with the absence of this feature in these Asian cultures has led to the speculation that the core features of the disorder are changing and the conclusion that the fear of fatness that is required for the diagnosis of anorexia nervosa in DSMIV may be a culturally dependent feature (Hsu and Lee 1993). This position is supported by evidence that other Asian countries that have a more Westernized culture such as Japan demonstrate weight phobia as a consistent feature of anorexia nervosa. This is also illustrated by the study of maternal perception of children's weight by Ohzeki and colleagues 
(1996), who found that Japanese mothers significantly underestimated the weight of their sons and daughters using silhouette drawings. Furthermore, Arab, Asian, Indian, and Pakistani women who live in the West and develop eating disorders also demonstrate weight phobia (Ahmad et al. 1994; Hill and Bhatti 1995; Mumford et al. 1991). Thus fear of fat may be a feature of anorexia nervosa that occurs in the context of a culture that overvalues thinness, and it is possible that as nations such as Malaysia, Pakistan, and India become more industrialized, weight phobia may become more common.

\section{Middle East}

Western attitudes about weight and body form have become prevalent in this region. Neumark-Sztainer, Palti, and Butler (1997), in a study of weight concerns and dieting behaviors in 334 Israeli adolescent girls, found high rates of past dieting $(74 \%)$ and current dieting (47\%), with no difference between girls from different countries of origin, including Arabic countries. However, maternal weight concerns about their daughters was higher among mothers from Europe/America or born in Israel as compared to mothers born in North Africa or the Middle East.

In a study of university students in Egypt, two cases of anorexia nervosa were documented among 1,050 cases that were reviewed (Okasha, Kamel, Sadek, Lotaif, and Bishry 1977). The clinical description of these cases was similar to those described in Western literature, but vomiting was more noticeable than restrictive dieting, and the response to treatment was better. Another study compared eating attitudes among Arab female students of both London and Cairo universities: in this study, Nasser (1986) identified 6 cases of bulimia nervosa in the London sample of 50 , with none found in the Cairo sample of 60 subjects. This difference was attributed to the impact of exposure to Western values. Another study of students at the American University in Cairo found that body shape preferences of Arab students showed a clear preference for thinness, as well as dissatisfaction among the female students with their current body shape (Ford, Dolan, and Evans 1990). It was speculated that the Western influences of this academic setting might promote more body dissatisfaction among these students.

\section{Africa}

Recent research suggests that Blacks within Africa may also be trending toward unhealthy eating attitudes and behaviors. An earlier study in South Africa in the late 1970s documented a 20-fold increase in admissions during the 5 years prior to the study (Norris 1979). Yet another study of anorexia nervosa in Johannesburg, South Africa, found a prevalence rate of $2.9 \%$ (Ballot et al. 1981). A recent study compared college students from several ethnic groups within South Africa and found that Black students scored significantly higher than Caucasian, Asian, and mixed ethnicity students on measures of abnormal eating attitudes (i.e., the EAT-40 and the Bulimic Investigatory Test) (le Grange, Telch, and Tibbs 1998). This finding is surprising in its contrast with previous notions that Black Africans may view obesity as more attractive when compared with the evaluations of Westerners (Furnham and Baguma 1994).

A study in northern Sudan found that anorexia nervosa was uncommon in that area, although the author conceded that it was difficult to determine the exact prevalence due to the reluctance of patients to seek treatment (El-Sarrag 1968). It was speculated that anorexia might be more uncommon there because the people are undernourished and because obesity is considered sexually attractive.

Another study compared Black, White, and mixed race schoolgirls in Zimbabwe (Hooper and Garner 1986). The authors found binge eating in all three groups, with the mixed race showing the strongest tendency to binge. Anorexic behavior was considerably more prevalent among the White and mixed race schoolgirls than among the Black schoolgirls.

\section{Australia}

Studies have suggested that Australian adolescents have risk factor levels that are sim- 
ilar to those found in the United States (Paxton et al. 1991; Rosen, Silberg, and Gross 1988). A recent study which included 3,001 interviews from a community-based Australian sample found that $1.6 \%$ regularly fasted or used strict dieting, $0.3 \%$ met criteria for bulimia nervosa, $1 \%$ had binge eating disorder, $3.2 \%$ had regular episodes of binge eating, and $0.8 \%$ purged (Hay 1998). Another study compared two groups of adolescent girls, from Anglo-Australian versus Greek Australian backgrounds, living in Australia for risk factors for eating disorders (Mildred, Paxton, and Wertheim 1995). This study found that both groups of girls had similar patterns of disordered eating risk factors. This finding was of interest since Greek girls living in Greece have been reported to have low levels of eating disorders (Fichter, Elton, Sourdi, Weyerer, and Koptagel-ilal 1988); thus one hypothesis was that Greek Australian girls may have assimilated Australian attitudes regarding ideal body size and eating behaviors, just as immigrant groups in the United States have been reported to develop higher risk for eating disorders as they acculturate.

\section{South America}

There have been few reports on the presence of eating disorders in Latin America and South America. Carlos (1972) reported almost no incidence of anorexia nervosa in Latin America. More recently, anorexic patients in Brazil have been described (Negrao and Cordas 1996), as well as anorexic and bulimic patients in Chile (Pumarino and Vivanco 1987). Rates of bulimia nervosa among highrisk groups of young adult females have been studied in Buenos Aires, Argentina: 31.5\% of dieters and $14.3 \%$ of exercisers were found to be bulimic compared with $2 \%$ of controls (Zuckerfeld, Fuchs, and Cormillot 1988).

\section{THE ROLE OF CULTURAL CHANGE IN EATING DISORDERS}

A number of hypotheses have been presented to account for the role that culture plays in the increasing trend toward a higher prevalence of eating disorders worldwide. DiNicola (1990) has proposed that anorexia nervosa is less a culture-specific syndrome than a culture-change syndrome of communities that are modernizing. According to this hypothesis, migrants and individuals in cultures that are changing are especially vulnerable to developing eating disorders. This theory is consistent with findings in immigrant groups who move into new cultures, as well as findings in culturally distinct groups for whom the prevailing socioeconomic and cultural norms are in the process of change as a result of industrialization or urbanization. Pumariega $(1986,1997)$ has also proposed that acculturation to Western ideals of attractiveness and body size is an increasing phenomenon that has a particularly powerful impact on developing adolescents, who are in the midst of establishing their psychological and cultural identity. Traditional cultures may have protective factors against the development of eating disorders, which may be rapidly eroded with exposure to Western-oriented values communicated through media and peer exposure. The main attitude relating to body size ideals that Western culture emphasizes may be that of body dissatisfaction. This is supported by the study by Gustavson and colleagues (1993), which found that the relationship between weight status and body size estimation using objective methods was essentially identical between American, Costa Rican, and Japanese students, just as it does not vary between clinical and nonclinical samples (Gustavson et al. 1990).

An additional cultural force that has changed in recent decades and that may influence the development of eating disorders is the changing role of women. Feminist theorists have also contributed to the conceptual basis for understanding the spread of risk for eating disorders. It is not by accident that the increase in the prevalence of eating disorders has occurred in parallel to significant changes in the role of women in Western culture and increasingly in other cultures around the globe. A number of authors (Boskind-White and White 1983; Bruch 1978; Gilbert and Thompson 1996; Gordon 1990; Pate et al. 
1992) have hypothesized that conflict between pressures to conform versus pressure to compete has placed adolescent females particularly at risk for these disorders.

It has been suggested that the emphasis in contemporary society on achievement and performance in women may increase their vulnerability to eating disorders. This emphasis contrasts greatly with traditional emphases on compliance, deference, and unassertiveness. History confirms the notion that eating disorders are more likely to develop at times when women have more opportunities (Bemporad 1997). Throughout history, self-starvation has been more common during periods of affluence but only if combined with greater freedom for women. For example, many modern Muslim cultures, where wealth has increased but women have very restricted lifestyles, do not report high prevalence rates of eating disorders. Contradictory role demands in today's society result in women's being pushed to be high achievers while they maintain their nurturance, femininity, and attractiveness. It is possible that eating disorders represent a means for women to respond to these apparently conflicting demands for success and attractiveness (Gilbert 1993).

Gilbert and Thompson (1996) analyze the available literature on eating disorders along four proposed feminist hypotheses of eating disorders: (a) a culture of thinness through which patriarchal society has effectively subjugated women; (b) weight as power and control for women, offering a means of expressing frustrated desire for power and control in other spheres of their lives; (c) anxieties about feminine achievement, with thinness expressing the conflict between pressures to achieve versus maintaining femininity; and (d) eating disorders as self-definition, with the body serving as a means of establishment of a woman's identity while assuming devalued roles of mother and wife. The role of a more aggressive and open sexual climate and roles for women in Western culture needs to be considered as an additional factor, given the increasing influence of the popular media in the loosening and commercialization of sexual mores. All of these factors should make us revisit psychoanalytic formulations (both classical Freudian and object relations) in the context of these new cultural mores and role expectations (Bruch 1973; Selvini-Palazzoli 1963; Sheehan and Summers 1948; Waller et al. 1940).

Katzman and Lee (1997) have attempted to integrate feminist with transcultural theories about the causes of anorexia. They propose that women "straddling two worlds" are at increased risk for developing eating disorders. They include generational, work-family, cultural, or traditional versus modern as examples of the conflicting worlds that women may have to try to reconcile. They propose that food denial may be a method to cope with the transitional process, disconnection from others, and oppression that women may experience in such situations. This theory is consistent with discussions here of the impact of cultural change on the development of eating disorders. This hypothesis of cultural transition or conflict as a major context for the development of eating disorders is consistent with the findings of increased rates reported among acculturating immigrant and minority groups, both non-White as well as from rural regions (Miller et al. 1999).

\section{CONCLUSIONS}

Eating disorders have occurred in many cultures throughout history and across many contemporary societies. Anorexia nervosa has previously been described as a possible "culture-bound syndrome," with roots in Western cultural values and conflicts (Prince 1983). Eating disorders are, in fact, more prevalent within various non-Western cultural groups than previously recognized as Western values are more widely adopted. A review of history suggests that eating disorders have been more likely to develop during periods of affluence that were coupled with more egalitarian opportunities for women (Bemporad 1997). In addition, historical and cross-cultural experiences suggest that cultural change itself may be associated with increased vulnerability to eating disorders, especially when values about 
physical aesthetics are involved. Such change may occur across time within a given society, or on an individual level, as when an immigrant moves into a new culture. As this review shows, eating disorders did not just emerge for the first time in the late 20th century in the United States, and they are not confined to Western cultures. They are significantly more widespread, and their individual presentations may be sensitive to the specific culture in which they develop. Future editions of the DSM would be strengthened by recognizing these disorders as being culturally based, if not culturally bound, in order to heighten attention to these issues.

Further research into the role of cultural factors associated with the development of eating disorders, and their interaction with biological and psychological factors, is critically needed. A number of questions merit study. Are different cultures associated with varying motivations for weight loss as well as varying presentations of eating disorders? With the current popularity of female athletics, how much of a role is athleticism playing in the development of eating disorders compared with the desire for a thin appearance? What buffers can be provided within subcultures to help prevent the development of eating disorders? What interventions, if any, have preventative value? What role do dietary differences across cultures, and dietary and activity changes resulting from acculturation, play in the development of eating disorders?

Understanding the role of cultural forces in the development of eating disorders suggests some general principles and guidelines for treatment and preventive intervention, especially with growing numbers of nonWhite patients. First, there is a clear need to strengthen and/or reinforce adaptive traditional cultural beliefs and practices, especially those that enhance self-esteem and self-concept. This may include strengthening ethnic identity and placing the body image in the broader context of self-image. This can be accomplished through a culturally competent approach to treatment and prevention. This approach emphasizes the development of knowledge, skills, and attitudes to enable the clinician to work across cultural differences and within the client's traditional cultural beliefs, as well as providing clinical care in programs which respect traditional beliefs and welcome their influence in program development (Pumariega and Cross 1997).

Another major emphasis in treatment and prevention should be to strengthen female identity, with broader options for role definition, identification, achievement, and ideals of feminine attractiveness. This may be accomplished in a variety of ways, including educational programs for girls, role-modeling, and conscious efforts to raise awareness of the need for healthy and realistic ideals of beauty. Promotion of moderation and flexibility in all aspects of health and adaptation should be emphasized, including physical, emotional, and spiritual.

Increased understanding of the role of culture in the development of eating disorders provide unique opportunities for proaction and prevention. Appreciation of the potential impact of cultural change may serve as a predictor that individuals and societies entering into periods of change may be at greater risk and may benefit from preventive measures. Although cultures will invariably change over time, the psychological and physical impact of cultural forces may hopefully be attenuated with conscious enlightened effort.

\section{REFERENCES}

Abrams, K. K., Allen, L. R., and Gray, J. J. Disordered eating attitudes and behaviors, psychological adjustment, and ethnic identity: A comparison of black and white female college students. International Fournal of Eating Disorders (1993) 14: 49-58.
Ahmad, S., Waller, G., and Verduyn, C. Eating attitudes among Asian schoolgirls: the role of perceived parental control. International Fournal of Eating Disorders (1994) 15:91-7.

Altabe, M. N. Issues in the assessment and treatment of body image disturbance in culturally 
diverse populations. In J. K. Thompson, ed., Body Image, Eating Disorders, and Obesity: An Integrative Guide for Assessment and Treatment (pp. 129-47). American Psychological Association, 1996.

AMERICAN PSYCHIATRIC ASSOCIATION. Diagnostic and Statistical Manual of Mental Disorders, 4th ed. American Psychiatric Association, 1994.

Andersen, A. E., and Hay, A. Racial and socioeconomic influences in anorexia nervosa and bulimia. International Fournal of Eating Disorders (1985) 4:479-87.

Ashley, C. D., Smith, J. F., Robinson, J. B., and RichaRDSON, M. T. Disordered eating in female collegiate athletes and collegiate females in an advanced program of study: A preliminary investigation. International fournal of Sport Nutrition (1996) 6:391-401.

Ballot, N. S., Delaney, N. E., Erskine, P. J., LANGRIDGE, P. J., SMIT, K., VAN NiEKERK, M. S., Winters, Z. E., and Wright, N. C. Anorexia nervosa: A prevalence study. South African Medical Fournal (1981) 59:992-3.

Becker, A. E., and Hamburg, P. Culture, the media, and eating disorders. Harvard Review of Psychiatry (1996) 4:163-7.

BELL, R. M. Holy Anorexia. University of Chicago Press, 1985.

BEMPORAD, J. R. Self-starvation through the ages: reflections on the pre-history of anorexia nervosa. International Fournal of Eating Disorders (1996) 19:217-37.

BEMPORAD, J. R. Cultural and historical aspects of eating disorders. Theoretical Medicine (1997) 18:401-20.

Bergh, C., and Sodersten, P. Anorexia nervosa: Rediscovery of a disorder. Lancet (1998) 351:1427-9.

Boskind-White, M., and White, W. C. Bulimarexia: The Binge/Purge Cycle. Norton, 1983.

BRUCH, H. Perceptual and conceptual disturbances in anorexia nervosa. Psychosomatic Medicine (1962) 24:287-94.

BRUCH, H. Anorexia nervosa and its differential diagnosis. Fournal of Nervous and Mental Disease (1966) 141:555-66.

Bruch, H. Eating Disorders: Obesity, Anorexia Nervosa and the Person Within. Basic Books, 1973.

BRUCH, H. The Golden Cage: The Enigma of Anorexia Nervosa. Harvard University Press, 1978.

BRUCH, H. Four decades of eating disorders. In D. M. Garner and P. E. Garfinkel, eds. Handbook of Psychotherapy for Anorexia Nervosa and Bulimia (pp. 7-18). Guildford Press, 1985.

BRUMBerG, J. J. Fasting Girls: The History of Anorexia Nervosa. Penguin Books, 1988.

Bryant-Waugh, R., and Lask, B. Anorexia nervosa in a group of Asian children living in Britain. British Fournal of Psychiatry (1991) 158: 229-33.
BUHRICH, N. Frequency of presentation of anorexia nervosa in Malaysia, Australia, and New Zealand. Fournal of Psychiatry (1981) 15:153-5.

Carlat, D. J., and Camargo, C. A. Review of bulimia nervosa in males. American fournal of Psychiatry (1991) 148:831-43.

CARLOS, A. S. Psychiatry in Latin America. British Fournal of Psychiatry (1972) 121:121-36.

CASTILlo, R. J. Culture and Mental Illness: A Client-Centered Approach. Pacific Grove, California: Brooks/Cole, 1997. Chapter 8: Eating Disorders, pp. 149-156.

Chamorro, R., and Florez-Ortiz, Y. Acculturation and disordered eating patterns among Mexican American women. International Fournal of Eating Disorders (2000) 28:125-9.

CRICHTON, P. Were the Roman emperors Claudius and Vitellius bulimic? International fournal of Eating Disorders (1996) 19:203-207.

DeZwaan, M., Mitchell, J. E., RayMOND, N. C., and SpITZER, R. L. Binge eating disorder: Clinical features and treatment of a new diagnosis. Harvard Review of Psychiatry (1994) 1(6): 310-25.

DiNicola, V. F. Anorexia multiforme: Self-starvation in historical and cultural context. Part II: Anorexia nervosa as a culture-reactive syndrome. Transcultural Psychiatric Research Review (1990) 27:245-86.

DOLAN, B. Cross-cultural aspects of anorexia nervosa and bulimia: A review. International Fournal of Eating Disorders (1991) 10:67-78.

Eagles, J. M., Johnston, M., Hunter, D., LobBan, M., and Millar, H. R. Increasing incidence of anorexia nervosa in the female population of Northeast Scotland. American Fournal of Psychiatry (1995) 152:1266-71.

EL-SARRAG, M. E. Psychiatry in the northern Sudan: A study in comparative psychiatry. British Fournal of Psychiatry (1968) 114:946-8.

Fichter, M. M., Elton, M., SOURdi, L., Weyerer, S., and Koptagel-ILal, G. Anorexia nervosa in Greek and Turkish adolescents. European Archives of Psychiatry and Neurological Sciences (1988) 237:200-8.

Fichter, M. M., WeYERER, S., SOURDI, L., and SouRDI, Z. The epidemiology of anorexia nervosa: A comparison of Greek adolescents living in Germany and Greek adolescents living in Greece. In P. L. Darby, P. E. Garfinkel, D. M. Gaines, and D. V. Coscina. Anorexia Nervosa: Recent Developments in Research (pp. 95-105). Alan R. Liss, 1983.

Fisher, M., Pastore, D., SChNeider, M., Pegler, C., and Napolitano, B. Eating attitudes in urban and suburban adolescents. International Fournal of Eating Disorders (1994) 16:67-74.

Fitzgibbons, M. L., Spring, B., AvelLOne, M. E., Blackman, L. R., Pingitore, R., and Stolley, M. R. Correlates of binge eating in 
Hispanic, black, and white women. International Fournal of Eating Disorders (1998) 24:43-52.

Ford, K. A., Dolan, B. M., and Evans, C. Cultural factors in the eating disorders: a study of body shape preferences of Arab students. Fournal of Psychosomatic Research (1990) 34:501-7.

Furnham, A., and Baguma, P. Cross-cultural differences in the evaluation of male and female body shapes. International Fournal of Eating Disorders (1994) 15:81-89.

Furnham, A., and Patel, R. The eating attitudes and behaviours of Asian and British schoolgirls: A pilot study. International fournal of Social Psychiatry (1994) 40:214-26.

GARD, M. C. E., and Freeman, C. P. The dismantling of a myth: A review of eating disorders and socioeconomic status. International fournal of Eating Disorders (1996) 20:1-12.

GARner, D. M., and Garfinkel, P. E. Socio-cultural factors in the development of anorexia nervosa. Psychological Medicine (1980) 10: 647-56.

Garner, D. M., Garfinkel, P. E., SCHWARTZ, D., and ThOMPSON, M. Cultural expectations of thinness in women. Psychological Reports (1980) 47:483-91.

GILBERT, S. C. Fear of success in anorexic young women. Fournal of Adolescent Health (1993) 14:380-3.

Gilbert, S., and Thompson, J. K. Feminist explanations of the development of eating disorders: Common themes, research findings, and methodological issues. Clinical Psychology: Science and Practice (1996) 3:183-202.

Gold, P. W., Gwirstman, H., Avgerinos, P. C., Nierman, L. K., Galluci, W. T., Kaye, W., Jimerson, D., EbERT, M., RitTmasTER, R., LoriauX, D. L., and Chorousos, G. P. Abnormal hypothalamic-pituitary-adrenal function in anorexia nervosa. New England Journal of Medicine (1986) 314:1335-42.

Gordon, R. A. Anorexia and Bulimia: Anatomy of a Social Epidemic. Basil Blackwell, 1990.

GreenberG, D. R., and LaPorte, D. J. Racial differences in body type preferences of men for women. International Fournal of Eating Disorders (1996) 19:275-8.

Greeno, C. G., WING, R. R., and SHIFFMAN, S. Binge antecedents in obese women with and without binge eating disorder. Fournal of Consulting and Clinical Psychology (2000) 68(1):95-102.

Gustavson, C., Gustavson, J., Pumariega, A. J., Herrera-Amighetti, L., Pate, J., Hester, C., and Gabaldon, M. P. Body image distortion among male and female American and Costa Rican students and female Japanese students. Perceptual and Motor Skills (1993) 76:127-30.

Gustavson, C., Gustavson, J., PumaRIEGa, A. J., Reinarz, D., DAmERon, R., GuStavson, A., Pappas, T., and McCaul, K. Body image distortion among male and female college and high school students and eating disordered patients. Perceptual and Motor Skills (1990) 71: $1003-10$.

Hall, S. K., Cousins, J. H., and Power, T. G. Self-concept and perceptions of attractiveness and body size amongst Mexican-American mothers and their daughters. International fournal of Obesity (1991) 15:567-75.

Hawkins, R. C., Turell, S., and JackSON, L. J. Desirable and undesirable masculine and feminine traits in relation to students' dietary tendencies and body image dissatisfaction. Sex Roles (1983) 9:705-24.

HAY, P. The epidemiology of eating disorder behaviors: An Australian community-based survey. International fournal of Eating Disorders (1998) 23:371-82.

Herzog, D. B., Newman, K. L., and WARSHAW, M. Body image dissatisfaction in homosexual and heterosexual males. Fournal of Nervous and Mental Disease (1991) 179:356-9.

Hill, A. J., and Bhatтi, R. Body shape perception and dieting in preadolescent British Asian girls: Links with eating disorders. International fournal of Eating Disorders (1995) 17:175-83.

HoEk, H. W. The incidence and prevalence of anorexia nervosa and bulimia nervosa in primary care. Psychological Medicine (1991) 21:455-60.

Hooper, M. S. H., and Garner, D. M. Application of the eating disorders inventory to a sample of black, white, and mixed race schoolgirls in Zimbabwe. The International Fournal of Eating Disorders (1986) 5:161-8.

Hsu, L. K. G. Are the eating disorders becoming more common in blacks. The International Journal of Eating Disorders (1987) 6:113-24.

HsU, L. K. G. Epidemiology of the eating disorders. In J. Yager, ed., The Psychiatric Clinics of North America: Eating Disorders (pp. 681-700). Saunders, 1996.

HsU, L. K. G., and LEE, S. Is weight phobia always necessary for a diagnosis of anorexia nervosa? American Fournal of Psychiatry (1993) 150: 1466-71.

Kamata, K., Nogami, Y., and Mомma, K. Binge-eating among female students. Fapanese Journal of Psychiatry and Neurology (1987) 41:151-2.

KaTZMAN, M. A., and LEE, S. Beyond body image: The integration of feminist and transcultural theories in the understanding of self-starvation. International fournal of Eating Disorders (1997) 22:385-94.

Kendall, R. E., Hall, D., Hailey, A. and BABIGIAN, H. The epidemiology of anorexia nervosa. Psychological Medicine (1973) 2:200-3.

KING, M. B., and BHugRA, D. Eating disorders: Lessons from a cross-cultural study. Psychological Medicine (1989) 19:955-8.

Kope, T. M., and SACK, W. H. Anorexia 
nervosa in Southeast Asian refugees: A report on three cases. Fournal of the American Academy of Child and Adolescent Psychiatry (1987) 26:795-7.

Kuboki, T., Nomura, S., IDE, M., Suematsu, H., and ARAKI, S. Epidemiological data on anorexia nervosa in Japan. Psychiatry Research (1996) 62:11-16.

LACEY, J. H. Anorexia nervosa and a bearded female saint. British Medical fournal (1982) 285: 1816-7.

LACEY, J. H., and DOLAN, B. M. Bulimia in British blacks and Asians: A catchment area study. British Fournal of Psychiatry (1988) 152:73-9.

LAWLOR, B. A., BURKET, R. C., and HODGIN, J. A. Eating disorders in American black men. Fournal of National Medical Association (1987) 79: 984-6.

LE Grange, D., Telch, C. F., and Agras, W. S. Eating and general psychopathology in a sample of Caucasian and ethnic minority subjects. International Fournal of Eating Disorders (1997) 21: 285-93.

Le Grange, D., Telch, C. F., and Tibbs, J. Eating attitudes and behaviors in 1,435 South African Caucasian and non-Caucasian college students. American Fournal of Psychiatry (1998) 155: 250-4.

LitTlewood, R. Psychopathology and personal agency: Modernity, culture change and eating disorders in South Asian societies. British Fournal of Medical Psychology (1995) 68:45-63.

Lucero, K., Hicks, R. A., Bramlette, J., Brassington, G. S., and Welter, M. G. Frequency of eating problems among Asian and Caucasian college women. Psychological Reports (1992) 7: 255-8.

Maloney, M. J., McGuire, J., Daniels, S. R., and SPECKER, B. Dieting behavior and eating attitudes in children. Pediatrics (1989) 84:482-9.

McCourt, J., and Waller, G. Developmental role of perceived parental control in the eating psychopathology of Asian and Caucasian schoolgirls. International Fournal of Eating Disorders (1995) 17:277-82.

MicKALIDE, A. D. Sociocultural factors influencing weight among males. In A. Andersen, ed., Males with Eating Disorders (pp. 30-9). Brunner/ Mazel, 1990.

Mildred, H., Paxton, S. J., and WerTHEIM, E. H. Risk factors for eating disorders in Greek- and Anglo-Australian adolescent girls. International fournal of Eating Disorders (1995) 17: 91-6.

Miller, M. N., Verhegge, R., Miller, B., and Pumariega, A. J. Assessment of risk of eating disorders among adolescents in Appalachia. Fournal of the American Academy of Child and Adolescent Psychiatry (1999) 38:437-443.

Minuchin, S., Rosman, B. L., and BAKer,
L. Psychosomatic Families: Anorexia Nervosa in Context. Harvard University Press, 1978.

Mumford, D. B., Whitehouse, A. M., and CHOUdrY, I. Y. Survey of eating disorders in English-medium schools in Lahore, Pakistan. International Fournal of Eating Disorders (1992) 11: 173-84.

Mumford, D. B., Whitehouse, A. M., and Platts, M. Sociocultural correlates of eating disorders among Asian schoolgirls in Bradford. British fournal of Psychiatry (1991) 158:222-8.

NAKANE, A., and UMINO, M. Psychopathology of anorexia nervosa in young adolescence. Fapanese Fournal of Psychiatry and Neurology (1987) 41:153.

NASSER, M. Comparative study of the prevalence of abnormal eating attitudes among Arab female students of both London and Cairo universities. Psychological Medicine (1986) 16:621-5.

NASSER, M. Eating disorders: the cultural dimension. Social Psychiatry and Psychiatric Epidemiology (1988) 23:184-7.

NASSER, M. A prescription of vomiting: Historical footnotes. International fournal of Eating Disorders (1993) 13:129-31.

Negrao, A. B., and Cordas, T. A. Clinical characteristics and course of anorexia nervosa in Latin America, a Brazilian sample. Psychiatry Research (1996) 62:17-21.

Neumark-SzTainer, D., Palti, H., and BUTLER, R. Weight concerns and dieting behaviors among high school girls in Israel. fournal of Adolescent Health (1997) 16:53-9.

Norring, C., and Sohlberg, S. Eating disorder inventory in Sweden: Description, crosscultural comparison, and clinical utility. Acta Psychiatrica Scandinavica (1988) 78:567-75.

NoRRIS, D. L. Clinical diagnostic criteria for primary anorexia nervosa. South African Medical Fournal (1979) 56:987-93.

NYLANDER, J. The feeling of being fat and dieting in a school population. Acta Socio-medica Scandinavica (1971) 1:17-26.

Ohzeki, T., Otahara, H., Hanaki, K., Urashima, H., Tsukuda, T., Tanaka, Y., and SHIRAKI, K. Maternal perception of children's weight in relation to eating disorders. Acta Psychiatrica Scandinavica (1996) 94:279-80.

Okasha, A., Kamel, M., SadeK, A., LOTAIF, F., and BISHRY, Z. Psychiatric morbidity among university students in Egypt. British fournal of Psychiatry (1977) 131:149-54.

Olivardia, R., Pope, H. G., JR., MangWETH, B., and Hudson, J. I. Eating disorders in college men. American fournal of Psychiatry (1995) 152:1279-85.

ONG, Y. L., Tsoi, W. F., and CHEAH, J. S. A clinical and psychosocial study of seven cases of anorexia nervosa in Singapore. Singapore Medical Fournal (1982) 23:255-61. 
Pate, J. E., Pumariega, A. J., Hester, C., and GARNER, D. Cross-cultural patterns in eating disorders: A review. Fournal of the American Academy of Child and Adolescent Psychiatry (1992) 31:802-9.

Paxton, S. J., Wertheim, E. H., GibBONS, K., SzMukleR, G. I., Hillier, L., and PETROVICH, J. L. Body image satisfaction, dieting beliefs and weight loss behaviors in adolescent girls and boys. Fournal of Youth and Adolescence (1991) 20:361-79.

PRINCE, R. Is anorexia nervosa a culturebound syndrome? Transcultural Psychiatric Research Review (1983) 20:299-300.

Pumariega, A. J. Acculturation and Eating Attitudes in Adolescent Girls: A Comparative and Correlational Study. Fournal of the American Academy of Child and Adolescent Psychiatry (1986) 25: 276-9.

Pumariega, A. J. Body dissatisfaction among Hispanic and Asian-American girls [Letter to the editor]. Fournal of Adolescent Health (1997) 21:1.

Pumariega, A. J., and Cross, T. L. Cultural competence in child psychiatry. In J. Noshpitz and N. Alessi, eds., Handbook of Child and Adolescent Psychiatry (Vol. 4, pp. 473-84). Wiley, 1997.

Pumariega, A. J., Edwards, P., and MitCHELl C. B. Anorexia nervosa in black adolescents. Fournal of the American Academy of Child Psychiatry (1984) 23:111-4.

Pumariega, A. J., Gustavson, C. R., Gustavson, J. C., Motes, P. S., and Ayers, S. Eating attitudes in African-American women: The Essence Eating Disorders Survey. Eating Disorders (1994) 2:5-16.

Pumarino, H., and Vivanco, N. Appetite and eating disorders: An increasing pathology? Revista Medica de Chile (1987) 115:785-7.

Rathner, G., and Messner, K. Detection of eating disorders in a small rural town: An epidemiological study. Psychological Medicine (1993) 23: 175-84.

Ritenbaugh, C., Shisslak, C., and PRINCE, R. A cross-cultural review in regard to DSM-IV. In J. E. Mezzich, H. Fabrega, A. Kleinman, and D. Perron, eds., Culture and Psychiatric Diagnosis: A DSM-IV Perspective. Washington, D.C.: APA Press, 1996, Chapter 23, pp. 171-186.

RobINSON, P., and ANDERSEN, A. Anorexia nervosa in American blacks. Fournal of Psychiatric Research (1985) 19:183-8.

Robinson, T. N., Killen, J. D., LiTt, I. F., Hammer, L. D., Wilson, D. M., Haydel, K. F., HaYwaRd, C., and TAYLOR, C. B. Ethnicity and body dissatisfaction: Are Hispanic and Asian girls at increased risk for eating disorders? Fournal of Adolescent Health (1996) 19:384-93.

Rolls, B. J., Fedoroff, I. C., and GuTHRIE, J. F. Gender differences in eating behavior and body weight regulation. Health Psychology (1991) 10:133-42.

Rosen, L. W., Shafer, C. L., Dummer, G. M., Cross, L. K., Deuman, G. W., and MalmBERG, S. R. Prevalence of pathogenic weight-control behaviors among Native American women and girls. International Fournal of Eating Disorders (1988) 7:807-11.

Rosen, J. C., Silberg, N. T., and Gross, J. Eating Attitudes Test and Eating Disorder Inventory: Norms for adolescent girls and boys. Fournal of Consulting and Clinical Psychology (1988) 56: 305-8.

Rowland, C. Anorexia and obesity. International Psychiatry Clinics (1970) 7:37-137.

RUCKER, C. E., and CASH, T. F. Body images, body-size perceptions, and eating behaviors among African American and White college women. International Fournal of Eating Disorders (1992) 12:291-9.

Russell, G. F. M. Bulimia nervosa: An ominous variant of anorexia nervosa. Psychological Medicine (1979) 9:429-48.

RUSSELL, G. F. M. The changing nature of anorexia nervosa: An introduction to the conference. Fournal of Psychiatric Research (1985) 19: $101-9$.

Russell, G. F. M. The history of bulimia nervosa. In D. M. Garner and P. E. Garfinkel, eds., Handbook of Treatment for Eating Disorders (pp. 11-24). Guilford Press, 1997.

SCHREIBER, G. B., Robins, M., STRIEGELMoore, R., Obarzanek, E., Morrison, J. A., and WRIGHT, D. J. Weight modification efforts reported by black and white pre-adolescent girls: National Heart, Lung, and Blood Institute Growth and Health Study. Pediatrics (1996) 98:63-70.

Selvini-Palazzoli, M. L'Anoressia Mentale. Feltunelli, 1963.

SheEHAN, M. L., and Summers, V. L. The syndrome of hypopituitarism. Quarterly fournal of Medicine (1948) 18:319-78.

SILBER, T. J. Anorexia nervosa in blacks and Hispanics. International Fournal of Eating Disorders (1986) 5:121-8.

Silberstein, L. R., MishKind, M. E., STRIEGEL-MoOre, R. H., TIMKO, C., and Rodin, J. Men and their bodies: A comparison of homosexual and heterosexual men. Psychosomatic Medicine (1989) 51:337-46.

SILVERMAN, J. A. Anorexia nervosa: Historical perspective on treatment. In D. M. Garner and P. E. Garfinkel, eds., Handbook of Treatment for Eating Disorders (pp. 3-10). Guilford Press, 1997.

SNOW, J. T., and HARRIS, M. B. Disordered eating in Southwestern Pueblo Indians and Hispanics. Fournal of Adolescence (1989) 12:329-36.

SONTAG, S. Illness as Metaphor. Farrar, Straus and Giroux, 1978.

STeinhausen, H. C. Transcultural com- 
parison of eating attitudes in young females and anorectic patients. Archiv fur Psychiatrie und Nervenkrankheiten (1984) 234:198-201.

Stice, E., Schupak-Neuberg, K., Shaw, H. E., and STEIN, R. I. Relation of media exposure to eating disorder symptomatology: An examination of mediating mechanisms. Fournal of Abnormal Psychology (1994) 103:836-40.

STriegel-Moore, R., Schreiber, G. B., Pike, K. M., Wilfley, D. E., and Rodin, J. Drive for thinness in black and white preadolescent girls. International Fournal of Eating Disorders (1995) 18: $59-69$.

Striegel-Moore, R. H., Wilfley, D. E., Pike, K. M., Dohm, F. A., and Fairburn, C. G. Recurrent binge eating in black American women. Archives of Family Medicine (2000) 9(1):83-7.

Suematsu, H., Ishikawa, H., Kuboki, T., and ITO, T. Statistical studies on anorexia nervosa in Japan: Detailed clinical data on 1,011 patients. Psychotherapy and Psychosomatics (1985) 43: 96-103.

Swift, W. J., and LeTven, R. Bulimia and the basic fault: A psychoanalytic interpretation of the binging vomiting syndrome. Fournal of the American Academy of Child and Adolescent Psychiatry (1984) 23:483-97.

ThEANDER, S. Anorexia nervosa: A psychiatric investigation of 94 female patients. Acta Psychiatrica Scandinavica (1970) 214:1-194.

Thomas, V. G. Body image satisfaction among Black women. Fournal of Social Psychology (1989) 129:107-12.

ThOMPSON, J. K. Body image, eating disorders, and obesity: An emerging synthesis. In J. K.
Thompson, ed., Body Image, Eating Disorders, and Obesity: An Integrative Guide for Assessment and Treatment (pp. 1-20). American Psychological Association, 1996.

VAN Den BRoucke, S., and VANDEREYCKEN, W. Risk factors for the development of eating disorders in adolescent exchange students: An exploratory survey. Fournal of Adolescence (1986) 9:145-50.

Waller, J. V., Kaufman, M. R., and Deutsch, F. Anorexia nervosa: A psychosomatic entity. Psychosomatic Medicine (1940) 2:3-16.

WALsh, B. T. Eating disorders. In A. Tasman, J. Kay, and J. A. Lieberman, eds., Psychiatry (Vol. 2, pp. 1202-1216). Saunders, 1997.

WARREN, M. P., and VANDE WIELE, R. L. Clinical and metabolic features of anorexia nervosa. American Fournal of Obstetrics and Gynecology (1973) 117:435-9.

Willi, J., Giacometti, G., and LIMACHER, B. Update on the epidemiology of anorexia nervosa in a defined region of Switzerland. American Fournal of Psychiatry (1990) 147:1514-7.

WILLI, J., and Grossman, S. Epidemiology of anorexia nervosa in a defined region of Switzerland. American Fournal of Psychiatry (1983) 140: 564-7.

Yates, A. Current perspectives on the eating disorders: I. History, psychological and biological aspects. Fournal of the American Academy of Child and Adolescent Psychiatry (1989) 28:813-28.

ZUCKERFELD, R., FUCHS, A., and CORMILLOT, A. Characterization and detection of bulimia in the city of Buenos Aires. Acta Psiquiatrica y Psicologica de America Latina (1988) 34:298-302. 